\title{
MASS COMMUNICATIONS: FROM CLASSICS TO THE VIRTUAL MODELS
}

\author{
ANRIETA KARAPETYAN
}

\section{Introduction}

The main objective of the study is to comprehend the fundamental differences between virtual communication models and classical communication models (Classic Linear and Interactive or circular), as well as consider their components as effective and necessary for the current period. We try to find out whether the virtual communication models gradually replace classical communication. The study's other point is that both classical and virtual communications coexist, which are combined in modern practice. The paper also reexamines the ordinary communication models to find out the existence of elements that could help to establish Internet-based communication models.

\section{Understanding Communication}

Communication originated in prehistoric times. Cave paintings are some of its visual representations (Schramm, 1988). Others state that communication in its modern frames is an invention of the nineteenth century, created together with ideologies and technologies (Mattelart, 1996). Researchers discuss communication as a pervasive phenomenon, identifiable for humans as well as animals, in all times and all places (Budd \& Ruben, 1972). There is some literature discussing communication as a basis of individual and social formation and transformation (Schiller, 1996)

Communication is the transfer of meanings, thoughts or emotions between individuals through a common system of symbols. Several books, articles and studies offer and discuss several other definitions of communication. However, all the definitions of communication seem to be invariably controversial. The notion of communication in ancient did not refer to transfer, transmission, interaction or dialogue, but rather pointed to acknowledging and performing specific social functions and group memberships, or to knowing and utilizing concrete technical devices for conveying specific social functions and group memberships. ${ }^{1}$

Communication is defined as the process by which we assign and convey meaning in an attempt to create shared understanding. This process requires a vast repertoire of skills in intrapersonal and interpersonal processing, listening,

\footnotetext{
${ }^{1}$ Nastasia D., Rakow, L., What is communication? Unsettling a priori and a posteriori approach, The International Communication Association, Philosophy of Communication Division, 2005, p. 4-10.
} 
observing, speaking, questioning, analyzing, and evaluating. Usage of these processes has been always developing and transfers to all areas of modern life: home, school, community, work, and beyond. Communication exactly occurs through collaboration and cooperation. ${ }^{2}$

Besides the above-mentioned definitions of communication, it is also defined as a relationship between phenomena that may respectively belong to one or differentiated systems, and communication supports a system or interaction between subsystems, creating a system at a higher, generalized level. ${ }^{3}$

Ordway Tead (1959) thinks communication is a composite of information given and received out of a learning experience. In this, certain attitudes, knowledge, and skills change, carving with them alterations of behavior and listening efforts by all involved, a sympathetic fresh examination of issues by the communicator himself, sensitive interacting points of view, leading to a higher level of a shared understanding and common intention.

Based on the analyses of the literature, we suggest the complex definition of communication: communication is the exchange of information and the transmission of meanings, it is the sum of all the actions person does when he wants to create understanding in the mind of another, the practice and product of providing information to an unknown audience. It assumes a systematic and continuous process. The rest of the paper follows this definition.

In addition to these definitions, there are several functions of communication represented as follow:

- Cognitive function, which refers to mental processes involved in the acquisition of knowledge, manipulation of information, and reasoning. It includes the domains of perception, recall, learning, attention, language abilities, etc. ${ }^{4}$

- Cognitive function, including the domains of perception; however, perception is considered to be a separate function and, in a word, it is all about how the same message can be interpreted differently by different people. It has already been most adequately reviewed (Fletcher 1953; Miller 1951). ${ }^{5}$ Stump and Fieser (2003) write that the contents of the human mind can all be reduced also to the materials that are given to us by the senses and experience. Perreault and McCarthy (2005) noticed in their researches that people apply selective processes in each communication. ${ }^{6}$

- Predictivity, which acts in a way to take control of behavior of communicators. This means that from the known factors and relationships in communica-

${ }^{2}$ Santandreu R. J., Shurden, S., Shurden, The complexity of communication, Journal of Case Studies in Education, Lander University, [Watched: 15.07.2020], Source: https://files.eric.ed.gov/fulltext/ EJ1057194.pdf, p. 5-8.

${ }^{3}$ Атанесян А. В. Актуальные проблемы современных политических и конфликтных коммуникаций. Ер.: Изд-во ЕГУ, 2008, с. 9-15.

${ }_{5}^{4}$ Relvin R., Cognition: Theory and Practice, Hardcover - International Edition, 2012, p. 20-30.

${ }^{5}$ Broadbent D. E., Perception and communication, Applied Psychology, Unit of the Medical Research Council, Cambridge, National Federation of the Blind (NFB), 2011, p. 10-11.

${ }^{6}$ Amodu L. O., Perception: A Determinant for Effective Communication, An African Journal of Philosophy, 9 (1), 2006, p. 148-153. 
tion we can make some relative guesses about outcomes of communication. ${ }^{7}$

- Motivation is the function of a stimulating communicator to take action that will accomplish the desired goal. It is clarifying "what is to be done", "what can be done" to improve the process of communication.

Communication performs several other functions as well, such as information, integrative, instructive, etc. It can also affect human socialization, motivation, educating persuasion, preservation, etc.

It is important to understand that none of these functions should be considered to be more important than the others. The levels of communication also can be different depending on the number of communicators: intrapersonal (human is communicating within himself), interpersonal (communication between two or more persons), small group (not so large amount of people and common goals of communication), public (comparatively large audience) and mass (using mass media). ${ }^{8}$ Each level of communication has its own probability of feedback availability. These levels and functions are manifested not only during the process of communication but also before or after it.

\section{Classical models of communication}

All of the components of communication are included in the models of communication referring to the visual representation of the communication process and not only. There are many linear and circular communication models, which have some specific features for their communication era, but the above-listed models are the main ones allowing us to make conclusions about the transformation of communication models.

The ancient communication model, which describes the process of communication is considered to be a speaker-centered model. Proposed by Aristotele, it has been the most influential model during the next 2,300 years. According to Aristotle, human communication has three main components: logos (logical arguments), pathos (emotional appeals), and ethos (good character of the speaker). This is the first linear communication model: a one-way process where a sender transfers the messages and a receiver gets them without giving a response/feedback. Aristotle's "model is actually more applicable to public speaking and mass communication than interpersonal communication". 9 Based on this model, many other communication models have arisen. Reasons for that are as follows: 1. these three concepts are not enough to define the process of communication; 2. several additional channels are developed, which provide alternative communication ways and types.

Lasswell's communication model (1948) is the second well-known model.

\footnotetext{
${ }^{7}$ Почепцов Г. Г. Теория коммуникации. М.: Рефл-бук, 2001, с. 40-48.

${ }^{8}$ Kulczycki E., Communication History and Its Research Subject, Adam Mickiewicz University, 2014, p. 133.

9 Adhikary N. M., The Sadharanikaran Model, and Aristotle's Model of Communication: A Comparative Study, Vol. 2, No. 1, Serial No. 2, 2008, p. 75.
} 
A convenient way to describe an act of communication is to answer some questions. The scientific study of the process of communication tends to concentrate upon one or another of these questions. Who/Says What/In Which Channel/To Whom/With What Effect?. ${ }^{10}$ Obviously, Lasswell pays attention to the channel and the effect of communication by adding two additional components. It represents communication in which various senders (who) and receivers (to whom) are connected with each other. If we think about the channel, we must notice that even in Lasswell's time there were many communication channels which could help human to communicate with each other. The earliest channel is surely Face-to-Face or Personal Communication. The communication model proposed by Lasswell was known as Dance Model.

According to Lasswell, each communication channel has its own level and size of effect. However, this is a linear model of communication, because it describes one-way direction. Additionally, many important concepts came out of earlier efforts in this regard, which we have already seen in the communication model by Claude Elwood Shannon (1949). Previously it was considered to be a linear model, which had the following six components: sender, encoder, channel, noise, decoder, and receiver. Now we see Lasswell Model's restrictions in combination with this model. Shannon's model of communication points is the beginning of the modern field. We can find out that Shannon focused on the problem of how good was to encode the symbols that a sender wanted to transmit as information. ${ }^{11}$ This model is based on a telephone system, which is a channel, and as we see, he produced a formula showing how the bandwidth of the channel and its signal-to-noise ratio affected its capacity to carry signals.

According to Shannon's model of communication, there is a noise that can distort and manipulate the encoding of the symbol by the receiver. Although Shannon developed a very primitive communication model, Warren Weaver (1948) added an additional important feedback component to this model, which enables us to call this model a circular or an interactive model. This feedback helps senders and receivers to control, predict, and correct the communication process. It helps to decrease the effect of noise. It is obvious that Warren Weaver prompted research on new communication models from other scientific perspectives like Psychology and Sociology.

The next major communication model belongs to Charles Osgood, who paid special attention to the feedback and who worked on his model with Wilbur Schramm (1954, the Osgood-Schramm Model of Communication). This model is rather circular than linear; this type of communication can be intraper-

\footnotetext{
${ }^{10}$ Lasswel H., Structure and Function of Communication in Society, (ed. by J. Bryson. The Communication of Ideas), N.Y. 1948, p. 30-35.

${ }^{11}$ Fedaghi S. A., A Conceptual Foundation for the Shannon-Weaver Model of Communication, computer Engineering Department Kuwait University, International Journal of Soft Computing, 2012, p. 18-25.
} 
sonal and interpersonal and combined as well. Each communicator acts as a sender and a receiver at the same time, so we can consider them to be equal. The model includes three main components: encoding, decoding, and interpreting a message. The process might be endless. A certain degree of semantic noise (cultural differences, background, socioeconomics, education, and values) is a part of communication affecting both encoding and decoding. ${ }^{12}$

George Gerbner's Model of Communication (1956) emphasizes the importance of effects and context in the communication process. He proposes two dimensions in the process of communication: perceptual, and means and control dimension. In real life, a perceptual dimension is an event $(\mathrm{E})$ and it is perceived by man/communicator or machine (M). Thus, to start the process of communication, we need some event and a context. The event perceived by $\mathrm{M}$ becomes E1 (perceived message by $M$ ) which is only a part of the event because $M$ has perceived it according to his perception, mood, attitude, culture, etc.

Gerbner's model of communication helps to make the process of communication more insightful. ${ }^{13}$

It is obvious, that classical models of communication gradually became more descriptive in communication processes, and in $1957 \mathrm{~B}$. Westley and M. MacLean introduced their model of communication. The application of this model is more likely in the context of interpersonal and mass communication. Feedback is the feature of this model. While the feedback is direct and fast in interpersonal communication, it is indirect and slow in mass communication. The model also differentiates messages into purposive and non-purposive. ${ }^{14}$

\section{Asynchronous and Synchronous virtual communication}

The age of networks began in the 1960s, but the official birthday of the Internet is considered to be 1983. By 1990, there had been around 2500 hosts all over the world. On 6 August of 1991, the World Wide Web became publicly available. ${ }^{15}$ This set the stage for new communication models: computer-mediated - communication (CMC) models. The development of computer communication models enables us to understand virtual communication. The first part of them describes the competencies of the people engaging in virtual communication. The second focuses on the influence of the medium, such as media richness, emphasize the role of the medium as a major influence on communication, in a way that is sometimes referred to as technological determinism. Finally, the third one ana-

${ }^{12}$ Schramm W., The Science of Human Communication, Basic Books, Inc., New York, 1963, p. 40-45. 1967, p. 18-30.

Kent G., Graphic conceptual models and communication theory, Boston University

${ }^{4}$ Lacy S., The Westley-MacLean Model Revised: An Extension of a Conceptual Model for Communication Research, School of Journalism, Michigan State University East Lansing, Michigan, 1989, p. 20-24.

${ }^{15}$ Lakkaraju K., Sukthankar G., Wigand R. T., Social Interactions in Virtual Worlds: An Interdisciplinary Perspective. Cambridge University Press, 2018, p. 13-18. 
lyzes the relationship, virtual terms, and communities.

However, many of them claim, that it is necessary to have a new communication model, because the old models can not completely describe this new type of communication the main component of which is Virtual. This type of communication can be seen on a spectrum ranging from synchronous to asynchronous. ${ }^{16}$ Communication is synchronous when the sender and receiver respectively send and receive information simultaneously. Synchronous transmissions are synchronized by an external clock.

On the other hand, asynchronous transmissions are synchronized by special signals along with the transmission medium including face-to-face or phone communication, in short together at the same time (eg, video calls, social media chats- instant messaging, etc.). Synchronous CMC occurs in real-time and requires simultaneous participation while asynchronous CMC does not occur in real-time and, as a result, participants can communicate whenever they want. Thus, CMC is asynchronous when sending and receiving information between the sender and receiver do not necessarily happen at the same time instant. In other words, the information is related to a time lag. In this type of communication, people sometimes have plenty of time to formulate thoughts, and people can internalize information, research certain ideas or merely have extra time for contemplation (eg, email, text messaging). These types of communication can involve both significant delays and immediate reply. ${ }^{17}$

Visualization of the above discussed two processes is represented in picture 1.

Picture 1

The process of asynchronous and synchronous virtual communication.

Asynchronous - virtual communication

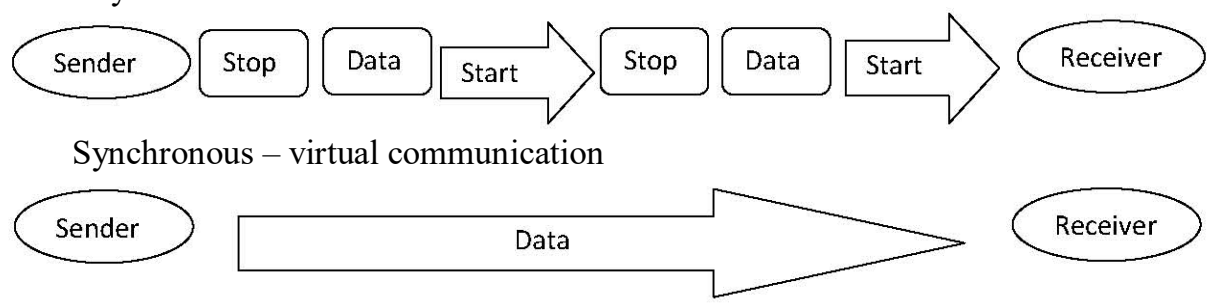

To conclude: virtual communication is "the process of creating, exchanging and perceiving the information, which aids encode, decode and transmit the messages by means of telecommunication network" and also includes "any human interaction, which is symbolic, text-based, directed or facilitated over digitally-based technologies".

${ }^{16}$ Sparso J., On Synchronous and Asynchronous Communication Paradigms, Technical University of Denmark, Computer Science and Engineering Section, Informatics and Mathematical Modelling, Richard Petersens Plads, Building 322, 2800 Lyngby, Denmark 2004, p. 30-40.

${ }^{17}$ Kumar K. A., Natarajan S., Acharaya B., Computer-mediated communication: A pathway to analyze social media communication trajectories, serials publications, 2017, p. 197-199. 
For explaining the Internet medium, new models of communication are required. Virtual communication models in turn lead to many alterations in the method people communicate. Each user can freely move within the virtual environment and manipulate communications in the virtual environment via a computer or mobile phone. All the users see a synchronized environment with all the changes. A virtual environment can directly affect the quality and type of communication process. Virtuality often confuses our sense of space in a way that has yet to be completely understood. ${ }^{18}$

First of all, it is considered to be so because virtuality changes our perception of communication space. The process and the effectiveness of communication depend on how communicators perceive the components of that process. American philosopher Susanne Langer notices that "Only a little part of reality, for a human being, is what is going on; the greater part is what he imagines in connection with the sights and sounds of the moment". It is obvious that virtuality changes all of them too. ${ }^{19}$

Most of the research in Virtual Reality is technology-centric. Very few studies highlight the importance of user perceptions and experiences in designing an effective Virtual Reality environment. The technology and human interaction in a virtual environment cannot be isolated or considered as two different entities. They have equal importance. It is important to consider human perceptions and experiences in line with technology for an effective understanding of Virtual communication. Some researchers explored that virtual reality further emphasized more on the importance of feedback in virtual reality by enhancing users' interactivity and immersion. From the perception of individuals, a variety of communication systems meet different people's needs based on their individual preferences ${ }^{20}$.

At the same time, there is some literature finding that human perception in a virtual environment has significant errors compared to the real physical environment. However, it is obvious that the way of human regarding, understanding, or interpreting communication have been changing in virtuality. Perception issues in virtual communication can lead to a number of distortions like biases or judgments of others, etc.

\section{Virtual models of communication}

The Age of Network of Networks that connects millions of computers worldwide began in 1960 with the introduction of Westley \& Maclean's $\mathrm{Model}^{21}$ and changed the process of communication by adding new components

\footnotetext{
${ }^{18}$ Kumar K. A., Natarajan S., Acharaya B, Computer-mediated communication: A pathway to analyze social media communication trajectories, serials publications, 2017, p. 197-199.

${ }^{19}$ Innis R. E., Signs of feeling: Susanne Langer's aesthetic model of minding, University of Massachusetts Lowel, PA 29, 2011, p. 50-52.

${ }^{20}$ Brindha K., Hanyu Yan K., Virtual Reality as a Communication Process: User Perceptions and Experiences, Sweden, Linnaeus university, 2017, p. 60-65.

${ }^{21}$ Lakkaraju K., Sukthankar G., Wigand R.T., Social Interactions in Virtual Worlds: An
} 
and elements to the existing. The communication does not begin when only one person starts to talk, but rather when a person responds selectively to his/her physical surroundings. So, it begins only when a person receives a message from the surroundings. As has been already mentioned, the model is also worthwhile for its account, both interpersonal and mass communications. The important part of this model, which let us consider it as a virtual model of communications is the feedback. The lack of feedback is a major problem in communication. One of the aspects is the type of feedback, with feedback outcome on one hand and feedback process on the other. The first type of feedback increases performance not only for the intrapersonal and interpersonal levels of communication but also for group and mass communication. Sometimes it is obtained as individual-level team feedback. The second type of feedback in a group context might contain not only information about behaviors, actions, or strategies but also information about interpersonal behaviors. Feedback is modeled as a special kind of dialogue moves that leads from one knowledge goal state or dialogue to another, which is triggered by fuzzy production rules. ${ }^{22}$

Reicher's (1995) model also called the SIDE model, focuses on the group level of communication: in a group context, in which social identity is salient, anonymity will facilitate influence among the group members. Using virtual communication, we simulated the creation of a virtual group and the setting of a CMC. This new model of communication is characterized by features such as the anonymity of users, the absence of non-verbal communication, physical separation, and temporal flexibility. Social influence originates from the need people have to agree with those sharing the same social identity and psychology in a group. ${ }^{23}$ It also makes communicators change their perceptions to find a balance in communication not only consciously, but also unconsciously. Integrated information from users' senses is crucial to the long-term success of virtual communication because it isn't solely visual.

One of the major models is Walther's (1996) Hyperpersonal Model of Communication. According to this model, while humans develop interpersonal relationships in face-to-face settings, it is possible for them to develop closer, hyperpersonal relationships in computer-mediated relationships (CMR). The hyperpersonal model of communication stands in contrast to earlier models of communication, which suggest that virtual communication is inferior to face-toface communication. According to Walther, this type of communication is based on a feedback loop: feedback, which starts with a message being sent. Senders imagine and visualize that feedback even before sending a message.

Interdisciplinary Perspective, Cambridge University Press, 2018, p. 13-18.

${ }^{22}$ Lacy S., The Westley-MacLean Model Revised: An Extension of a Conceptual Model for Communication Research, School of Journalism, Michigan State University, East Lansing, Michigan, 1989, p. 20-24.

${ }^{23}$ Reicher S. D., Spears R., Postmes T., A Social Identity Model of Deindividuation Phenomena, University of Amsterdam, European Review of Social Psychology, 1995, p. 162-168. 
They try to impress and portray themselves in the best possible light. Walther called this process «selective self-presentation». ${ }^{24}$

The next stage of the virtual communication process is when the message is received by another communicator - message-receiver. This process can be aided based upon the channel being used for virtual communication. Based on the fact that the sender has much more time to compose a message these computer-mediated channels allow greater selective self-presentation. Feedback is given between communicators aiding in the process of selective selfpresentation. This mentioned model considers that virtual communication, which is valuable in providing better communication and better first impressions. If communicators receive a cue that their message was poorly received, they can alter their form of self-presentation to be more attuned to the other sender's or receiver's preferences. ${ }^{25}$

Ultimately, this feedback loop could result in a hyperpersonal relationship in which communicators consistently present the desired form of self-based on the likes and dislikes of the other communicator. As we see, this model also emphasizes the interpersonal level of communication and the key component is the feedback, which starts with the first message being sent or before it.

Spitzberg ${ }^{26}$ recently developed his model of virtual communication, which is partly founded on the theoretical research of competence in interpersonal interaction, especially on the related motivation, knowledge and skills model of interpersonal competence. In addition to the other models, Spitzberg mentioned, that the virtual communication process takes place if there are some factors, and the interaction between communicators is based on these factors as well. The major factors are contextual, which include attributes of the interactants (attitude, belief, value, nationality, race, religion, gender, etc.), temporal attributes (e.g. the time stream, timing and sequencing of messages), attributes of relationship (type, quality, intensity, etc.), environmental attributes (place, situation, medium, etc.), and functional attributes (e.g. task, romance). According to Spitzberg, virtual communications not only change the user's perception about communication and transfermessages but also people virtually are more likely to traverse into cultures different from their own. ${ }^{27}$

Unlike the above-mentioned models focusing on the transmission of a message, McLuhan's famous model is concerned with the transformations in the relationship between message and context. A statement by Marshall McLuhan

${ }^{24}$ Walther J.B., Computer-mediated communication: Impersonal, interpersonal, and hypersonal interaction, University of California, Santa Barbara, 1996, p. 28-35.

${ }_{25}$ Walther J.B., Computer-mediated communication: Impersonal, interpersonal, and hypersonal interaction, University of California, Santa Barbara, 1996, p. 20-25.

26 Spitzberg B.H., A Model of Intercultural Communication Competence, WR Cupach SAGE Publications, Incorporated, 2000, p. 375-387.

${ }^{27}$ Spitzberg B.H., Preliminary development of a model and measure of computer-mediated communication (CMC) competence, Journal of Computer-Mediated Communication 11 (2), 2006, p. 629-666. 
"The medium is the message" examines the condition of the message's form. He wanted to signify content and character, and in this context, we can claim that virtuality is the medium itself, which represents the message, and sometimes it is a medium without a message, which is designed to extend human senses. ${ }^{28}$

\section{Conclusion}

The Internet has challenged the classical understanding of the communication process, so that understanding of the new communication processes, developed on and by means of the Internet, is critically important. The message factors in the virtual communication competence model are related to the attributes of message content. Messages may also vary regarding complexity, ambiguity, and other characteristics. The vitality factors are the level of interactivity of a medium, the adaptability of a medium for specific types of use, and the efficiency of a medium for different purposes. The final components of the virtual communication competence model are the outcomes associated with the level of competence in the virtual communication interactions of an individual. The typology of the outcomes may include the appropriateness and effectiveness of the interaction, as well as co-orientation (how well the received message was understood), the achieved level of satisfaction of the interactants, and relationship development. ${ }^{29}$ Hereby, classical models of communication are not so powerful to explain this new type of communication. It is obvious, that the virtual communication model's main components are the feedback and the effects, which depend on several factors and several channels are different. Modern scholars accept, that the process of communication is the same as the early communication process when the channel is not the virtual world (Lasswell's time (1902-1978), Shannon and Weaver Model (1949), Osgood's Model (1954), Schramm Model (1954), etc.). But in contrast to the classics, modern scholars concentrate their researches and studies on feedback, perception, and selfpresentation, which concern the predominant mode of communication process and communicator's behavior, and these are the main components in all levels of communication.

Key words: Mass communication, virtual communication, virtual environment, models of communication, feedback, self-presentation, virtual as the message

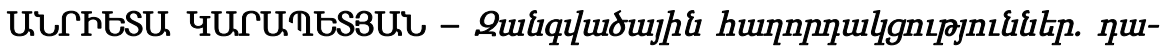

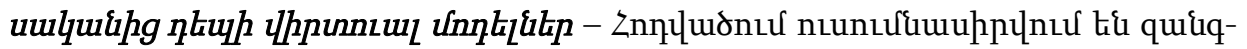

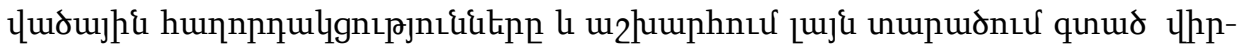

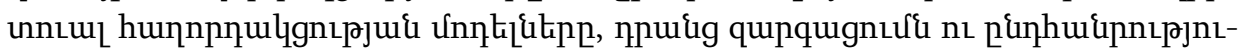

${ }^{28}$ Marchand P., Marshall McLuhan: The Medium and the Messenger, The MIT Press; Revised, Subsequent edition, The MIT Press ,1998, p. 111-121.

${ }_{29}$ Bubas G., Competence in Computer-Mediated Communication: An Evaluation and Potential Uses of a Self-Assessment Measure, International Communication Association Conference, Dresden, Germany, 2006, p. 5-15. 


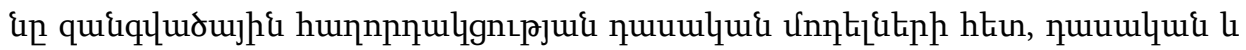

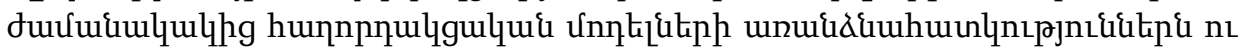

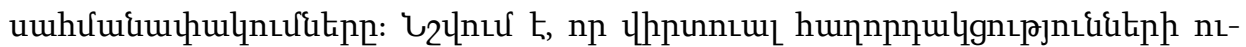

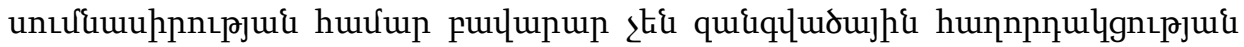

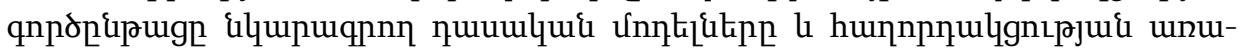

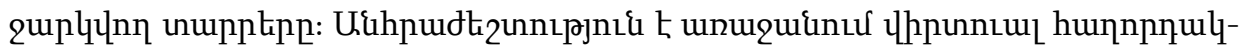

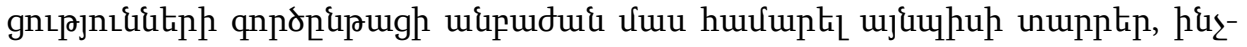

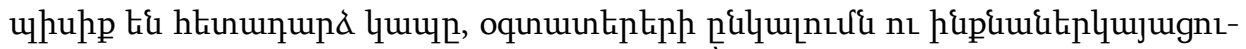

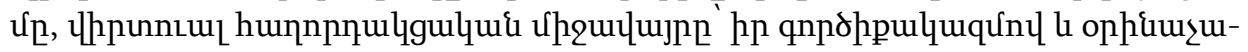

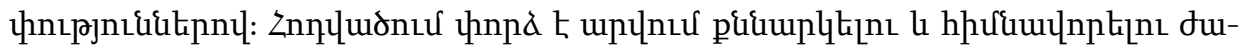

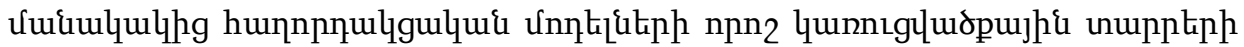
withpurtizunnıpjnikn:

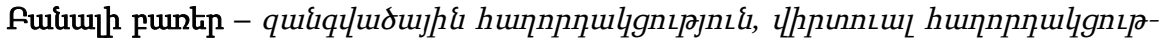

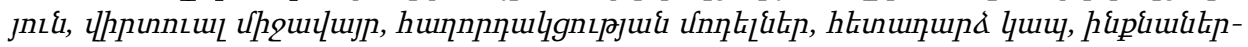
qujugnıl, thpunnumin npultu uhginnn

АНРИЕТА КАРАПЕТЯН - Массовые коммуникации: от классических до виртуальных моделей. - Статья посвящена широкому распространению массовых коммуникаций и их виртуальным моделям, особенностям и ограничениям, а также сравнению виртуальных и классических моделей. Для изучения виртуальных коммуникаций недостаточно описать соответствующие процессы в рамках классических моделей, а также включенных в них коммуникационных элементов. Чтобы полноценно описать современные коммуникационные процессы, предлагается дополнить классические модели такими элементами, как обратная связь, восприятие и саморепрезентация пользователя, а также виртуальное пространство коммуникации.

Ключевые слова: массовые коммуникации, виртуальная коммуникация, виртуальная среда, обратная связь, саморепрезентаиия, виртуальное как посредник

'LteplqujugultıL

qpupunultilt 26.08 .2020

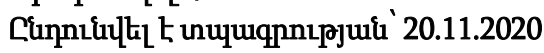




\begin{abstract}
The article is devoted to the widespread use of mass communications and their virtual models, features and limitations, as well as the comparison of virtual and classical models. To study virtual communications, it is not enough to describe the corresponding processes within the framework of classical models, as well as the communication elements included in them. In order to fully describe modern communication processes, it is proposed to supplement the classical models with such elements as feedback, perception and self-presentation of the user, as well as the virtual communication space.
\end{abstract}

Keywords: Mass communication, virtual communication, virtual environment, models of communication, feedback, self-presentation, virtual as the message

\title{
About Authors
}

Anrieta Karapetyan - PhD student of the Chair of Applied Sociology, Yerevan State University E mail: anrieta.karapetyan@ysumail.am

\section{REFERENCES}

Nastasia, D. \& Rakow, L. (2005). What is communication? Unsettling a priori and a posteriori approach, The International Communication Association, Philosophy of Communication Division, 4-10

Santandreu, R. J., Shurden, S. \& Shurden, M. (2011). The complexity of communication, Journal of Case Studies in Education, Lander University, 2. Retrieved from https://files.eric.ed.gov/fulltext/ EJ1057194.pdf, p. 5-8.

Atanesyan, A.V. (2008). Aktual'nye problemy sovremennykh politicheskikh i konfliktnykh kommunikacii. Yerevan. Izd.-vo EGU, 9-15

Relvin, R. (2012). Cognition: Theory and Practice, Hardcover - International Edition, 20-30 Broadbent, D. E. (2011). Perception and communication, Applied Psychology, Unit of the Medical Research Council, Cambridge, National Federation of the Blind (NFB), 10-11 Amodu, L. O. (2006). Perception: A Determinant for Effective Communication, An African Journal of Philosophy, 9 (1), 148-153. Doi: https://doi.org/10.4314/sophia.v9i1.38774 Pochepcov, G.G. (2001). Teoriya kommunikacii. Moscow, Refl-buk, 40-48

Kulczycki, E. (2014). Communication History and Its Research Subject, Adam Mickiewicz University, 133

Adhikary, N. M. (2008). The Sadharanikaran Model, and Aristotle's Model of Communication: A Comparative Study, Vol. 2, No. 1, Serial No. 2, 75. Doi:

https://doi.org/10.3126/bodhi.v2i1.2877

Lasswel, H. (1948). Structure and Function of Communication in Society, (ed. by J. Bryson. The Communication of Ideas), N.Y. 30-35

Fedaghi, S. A. (2012). A Conceptual Foundation for the Shannon-Weaver Model of Communication, computer Engineering Department Kuwait University, International Journal of Soft Computing, 18-25 
Schramm, W. (1963). The Science of Human Communication, Basic Books, Inc., New York, 40-45

Kent, G. (1967). Graphic conceptual models and communication theory, Boston University, 1830

Lacy, S. (1989). The Westley-MacLean Model Revised: An Extension of a Conceptual Model for Communication Research, School of Journalism, Michigan State University East Lansing, Michigan, 20-24

Lakkaraju, K., Sukthankar, G. \& Wigand R. T. (2018). Social Interactions in Virtual Worlds: An Interdisciplinary Perspective. Cambridge University Press, 13-18. Doi:

https://doi.org/10.1017/9781316422823

Sparso, J. (2004). On Synchronous and Asynchronous Communication Paradigms, Technical University of Denmark, 30-40

Kumar, K. A., Natarajan, S. \& Acharaya, B. (2017). Computer-mediated communication: A path-way to analyze social media communication trajectories, serials publications, 197-199 Innis, R. E. (2011). Signs of feeling: Susanne Langer's aesthetic model of minding, University of Massachusetts Lowell, PA 29, 50-52

Brindha, K. \& Hanyu Yan, K. (2017). Virtual Reality as a Communication Process: User Perceptions and Experiences, Sweden, Linnaeus university, 60-65

Lacy, S. (1989). The Westley-MacLean Model Revised: An Extension of a Conceptual Model for Communication Research, School of Journalism, Michigan State University, East Lansing, Michigan, 20-24

Reicher, S. D., Spears, R.\& Postmes, T. (1995). A Social Identity Model of Deindividuation Phenomena, University of Amsterdam, European Review of Social Psychology, 162-168. Doi: https://doi.org/10.1080/14792779443000049

Walther, J.B. (1996). Computer-mediated communication: Impersonal, interpersonal, and hyper-sonal interaction, University of California, Santa Barbara, 28-35

Spitzberg, B.H. (2000). A Model of Intercultural Communication Competence, WR Cupach SAGE Publications, Incorporated, 375-387

Spitzberg, B.H. (2006). Preliminary development of a model and measure of computermediated communication (CMC) competence, Journal of Computer-Mediated Communication 11 (2), 629-666. Doi: https://doi.org/10.1111/j.1083-6101.2006.00030.x

Marchand, P. (1998). Marshall McLuhan: The Medium and the Messenger, The MIT Press, 111-121

Bubas, G. (2006). Competence in Computer-Mediated Communication: An Evaluation and Potential Uses of a Self-Assessment Measure, International Communication Association Conference, Dresden, Germany, 5-15 